\title{
Acute and Chronic Effects of Particles on Hospital Admissions in New England
}

\section{Citation}

Kloog, Itai, Brent A. Coull, Antonella Zanobetti, Petros Koutrakis, and Joel D. Schwartz. 2012. Acute and chronic effects of particles on hospital admissions in New England. PLoS ONE 7(4): e34664.

\section{Published Version}

doi:10.1371/journal.pone.0034664

\section{Permanent link}

http://nrs.harvard.edu/urn-3:HUL.InstRepos:10056515

\section{Terms of Use}

This article was downloaded from Harvard University's DASH repository, and is made available under the terms and conditions applicable to Other Posted Material, as set forth at http:// nrs.harvard.edu/urn-3:HUL.InstRepos:dash.current.terms-of-use\#LAA

\section{Share Your Story}

The Harvard community has made this article openly available.

Please share how this access benefits you. Submit a story.

\section{Accessibility}




\title{
Acute and Chronic Effects of Particles on Hospital Admissions in New-England
}

\author{
Itai Kloog ${ }^{1 *}$, Brent A. Coull ${ }^{2}$, Antonella Zanobetti ${ }^{1}$, Petros Koutrakis ${ }^{1}$, Joel D. Schwartz ${ }^{1}$
}

1 Exposure, Epidemiology and Risk Program, Department of Environmental Health, Harvard School of Public Health, Boston, Massachusetts, United States of America, 2 Department of Biostatistics, Harvard School of Public Health, Boston, Massachusetts, United States of America

\begin{abstract}
Background: Many studies have reported significant associations between exposure to $\mathrm{PM}_{2.5}$ and hospital admissions, but all have focused on the effects of short-term exposure. In addition all these studies have relied on a limited number of $\mathrm{PM}_{2.5}$ monitors in their study regions, which introduces exposure error, and excludes rural and suburban populations from locations in which monitors are not available, reducing generalizability and potentially creating selection bias.

Methods: Using our novel prediction models for exposure combining land use regression with physical measurements (satellite aerosol optical depth) we investigated both the long and short term effects of PM $_{2.5}$ exposures on hospital admissions across New-England for all residents aged 65 and older. We performed separate Poisson regression analysis for each admission type: all respiratory, cardiovascular disease (CVD), stroke and diabetes. Daily admission counts in each zip code were regressed against long and short-term $\mathrm{PM}_{2.5}$ exposure, temperature, socio-economic data and a spline of time to control for seasonal trends in baseline risk.

Results: We observed associations between both short-term and long-term exposure to $\mathrm{PM}_{2.5}$ and hospitalization for all of the outcomes examined. In example, for respiratory diseases, for every $10-\mu \mathrm{g} / \mathrm{m}^{3}$ increase in short-term $\mathrm{PM}_{2.5}$ exposure there is a 0.70 percent increase in admissions $(C l=0.35$ to 0.52$)$ while concurrently for every $10-\mu \mathrm{g} / \mathrm{m}^{3}$ increase in long-term $P M_{2.5}$ exposure there is a 4.22 percent increase in admissions $(\mathrm{Cl}=1.06$ to 4.75$)$.

Conclusions: As with mortality studies, chronic exposure to particles is associated with substantially larger increases in hospital admissions than acute exposure and both can be detected simultaneously using our exposure models.
\end{abstract}

Citation: Kloog I, Coull BA, Zanobetti A, Koutrakis P, Schwartz JD (2012) Acute and Chronic Effects of Particles on Hospital Admissions in New-England. PLoS ONE 7(4): e34664. doi:10.1371/journal.pone.0034664

Editor: Mike B. Gravenor, University of Swansea, United Kingdom

Received September 28, 2011; Accepted March 6, 2012; Published April 17, 2012

Copyright: (c) 2012 Kloog et al. This is an open-access article distributed under the terms of the Creative Commons Attribution License, which permits unrestricted use, distribution, and reproduction in any medium, provided the original author and source are credited.

Funding: The research was supported by the Harvard Environmental Protection Agency (EPA) Center, Grants R-832416 and RD 83479801 , NIH grants ES00002 and ES012044. The funders had no role in study design, data collection and analysis, decision to publish, or preparation of the manuscript.

Competing Interests: The authors have declared that no competing interests exist.

* E-mail: ekloog@hsph.harvard.edu

\section{Introduction}

Short-term variations in air pollution have been associated with hospital admissions for various causes in cities all over the world $[1,2,3,4,5,6]$. These associations include admissions for respiratory disease $[7,8,9]$, ischemic heart disease-IHD [10,11], cardiovascular disease-CVD [7,12], myocardial infarction-MI [13,14], congestive heart failure-CHF [15,16], pneumonia [17,18], and diabetes [19,20].

For $\mathrm{PM}_{2.5}$ in particular Dominici and colleagues [21] reported associations with hospitalizations for multiple diseases, using single day average $\mathrm{PM}_{2.5}$. Zanobetti and colleagues [22] estimated the association between two-day mean $\mathrm{PM}_{2.5}$ and emergency hospital admissions for CVD,MI, CHF, respiratory disease, and diabetes in 26 US communities, and reported larger effect sizes than those reported in Dominici et al. [21]. There are currently, to the best of our knowledge, no published studies on the effects of long-term (chronic) particulate matter (PM) exposure and hospital admissions. There are however some studies that provide general evidence for long-term associations of air pollution with hospital admissions, although not specifically focusing on $\mathrm{PM}_{2.5}$
$[23,24,25,26]$. For example, Oudin and colleagues [25] investigated whether the effects of major risk factors for ischemic stroke were modified by long-term exposure to air pollution in Scania, southern Sweden. They found that in low level air pollution areas, the risk for ischemic stroke associated with diabetes seemed to increase with long-term exposure to air pollution. Hruba and colleuges [24] studied the effects of long-term exposure to air pollution on respiratory symptoms and respiratory hospitalization in a cross-sectional study of children. They showed found a significant increase in hospital admissions for asthma, bronchitis or pneumonia associated with increasing air pollution. Andersen and colleagues [26] studied the association between chronic exposure to traffic-related air pollution $\left(\mathrm{NO}_{2}\right)$ and incidence of diabetes. They found that chronic exposure to $\mathrm{NO}_{2}$ may contribute to the development of diabetes, especially in individuals with a healthy lifestyle, nonsmokers, and physically active individuals.

All previous studies have been limited by the lack of high resolution daily exposure data. Many early studies had only 1 in 3 day measurements, and locations without nearby monitors could not be analyzed at all. In addition all previous studies focused on 
short-term PM exposure and not long term (chronic) exposure or both.

We have recently presented a new method of assessing temporally-and spatially-resolved $\mathrm{PM}_{2.5}$ exposures for epidemiological studies which is an extension of existing land use models $[27,28]$. In this paper, we use our model predictions to study the association between $\mathrm{PM}_{2.5}$ exposure and hospital admissions among elderly (aged 65 and older from Medicare data) across New England, and to investigate the effects of both short term (acute) and long-term (chronic) exposure on these outcomes for the first time concurrently. In addition our study investigates the entire population of a region, rather than selected locations near monitoring sites as commonly done in previous studies.

\section{Methods}

\section{Study domain}

The presented study's spatial domain included the NewEngland region comprising the states of Connecticut, Maine, Massachusetts, New Hampshire, Rhode Island and Vermont, (Figure 1). The total area of New England is $186,460 \mathrm{~km}^{2}$. The total population in New-England as of 2010 is 14,444,865. The average size of population in New-England zip codes for the general population is 8130 and 1105 for people 65 and over. The median population is 3535 for the general population and 430 for people 65 and over [29].

\section{Data}

Exposure data. Land use regression (LUR) models provide good estimates of spatially resolved long term exposures, but are poor at capturing short term exposures. Due to its large spatial coverage and reliable repeated measurements, satellite remote sensing, provides another important tool for monitoring aerosols, particularly for areas and exposure scenarios where surface $\mathrm{PM}_{2.5}$ monitors are not available [30,31,32,33]. Using satellite derived aerosol optical depth (AOD) measurements allowed us to predict daily $\mathrm{PM}_{2.5}$ concentration levels across New England for 20002008 at a $10 \times 10 \mathrm{~km}$ spatial resolution [34]. This published model has been slightly updated to include nested regions in the yearly models and weights to account for non-random missingness in AOD.

In brief, we used day-specific calibrations of AOD data, using ground $\mathrm{PM}_{2.5}$ measurements from 78 monitoring sites in the EPA (Environmental Protection Agency) and IMPROVE (Interagency Monitoring of Protected Visual Environments) monitoring network to avoid prediction error due to changes in planetary boundary layer etc. previously noted by Paciorek et al. [28]. We also incorporated land use regression and meteorological variables (temperature, wind Speed, visibility, elevation, distance to major roads, percent of open space, point emissions and area emissions). To estimate $\mathrm{PM}_{2.5}$ concentrations in each grid cell on each day we start by calibrating the AOD-PM 2.5 relationship for each day using grid cells with both monitors and AOD values using mixed models with random slopes for day and nested regions. To validate our first model, the dataset was repeatedly randomly divided into $90 \%$ and $10 \%$ splits. Predictions for the held-out $10 \%$ of the data were made from the model fit of the remaining $90 \%$ of the data. This "out of sample" process was repeated ten times and crossvalidated $(\mathrm{CV}) \mathrm{R}^{2}$ values were computed. The first stage calibrations resulted in high out-of-sample $\mathrm{R}^{2}$ (mean out-of-sample $\left.\mathrm{R}^{2}=0.85\right)$. Later, we used a second model to address days when $A O D$ measures are not available (due to cloud coverage, snow etc...). We thus fit a model with a smooth function of latitude and longitude and a random intercept for each cell (similar to universal kriging) that takes advantage of the association of grid cells AOD values with $\mathrm{PM}_{2.5}$ monitoring located elsewhere, and the association with available AOD values in neighboring grid cells. Even for location-day combinations without AOD data our model performance was still excellent (mean out-of-sample $\mathrm{R}^{2}=0.81$ ). Importantly, these $\mathrm{R}^{2}$ are for daily observations, rather than monthly or yearly, values. By averaging our estimated daily exposures at each location we generated long term exposures. This enabled us to study both the short term and long term effects of ambient particles, respectively.

$\mathrm{PM}_{2.5}$ exposure data were generated by our prediction models. The New-England exposure dataset contains daily $\mathrm{PM}_{2.5}$ concentrations at a $10 \times 10 \mathrm{~km}$ spatial resolution across New-England for the whole study period (Figure 1). This data was matched to zipcodes using ArcGIS and SAS based on spatial location and date.

Hospital Admittance data. Individual hospital admittance records were obtained from the US Medicare program and covers hospitalization for all residents aged 65 and older, for all available years (2000-2006). There were around 3000 hospitals under the study area. We defined cases as those with an emergency admission and a primary discharge diagnosis of all respiratory (ICD 9 460-519), CVD (ICD 9 390-429), stroke (ICD 9 430-436) and diabetes (both primary and secondary admission cause) (ICD 9 250).

We choose broader areas of admissions, since one would expect broader areas of admission to produce less noisy estimates for two reasons. First, the counts are higher and therefore there is more power to examine CVD admissions than IHD admissions. Secondly, studies of misdiagnosis in hospital administrative records show that the broader the categories, the less misclassification there is, which would also eliminate noise and produce more stable results. For diabetes, which is a chronic condition, we looked at the rate of admission of subjects for any primary cause with diabetes as a secondary cause, as well as the small number of admissions with diabetes listed as the primary cause of admission. This allows us to examine whether long term exposure to particles is associated with higher rates of hospitalization of diabetics, as well as whether diabetics have higher rates of acute hospitalizations on high air pollution days.

These records included information such as age, sex, date of admission, race/ethnicity, and zipcode of residence. From this data, we constructed daily counts for each admission cause for each zip code. This allows us to examine the effects of both day-today contrasts within residential area, as well as long term contrasts across locations.

Covariates. Temperature data were obtained through the National Glimatic Data Center (NCDG) [35]. Only continuous operating stations with daily data running from 2000-2006 were used. Zipcodes were matched to the closest weather station for meteorological variables. All Socioeconomic variables were obtained through the U.S. Census Bureau Census from the 2000 social, economic and housing characteristics datasets [36]. Socio-economic variables used included the following zipcode level information: Percent of minorities, age, education (people with no high school education) and median income.

\section{Statistical Methods}

The admission counts by zip code were matched with our exposure estimates for each $10 \times 10 \mathrm{~km}$ grid cell it fell into. While short-term effects of air pollution are traditionally studied using Poisson log-linear models and long-term effects are estimated using the Cox proportional hazard model, we make use of the equivalence between Poisson regression and the piecewise constant 


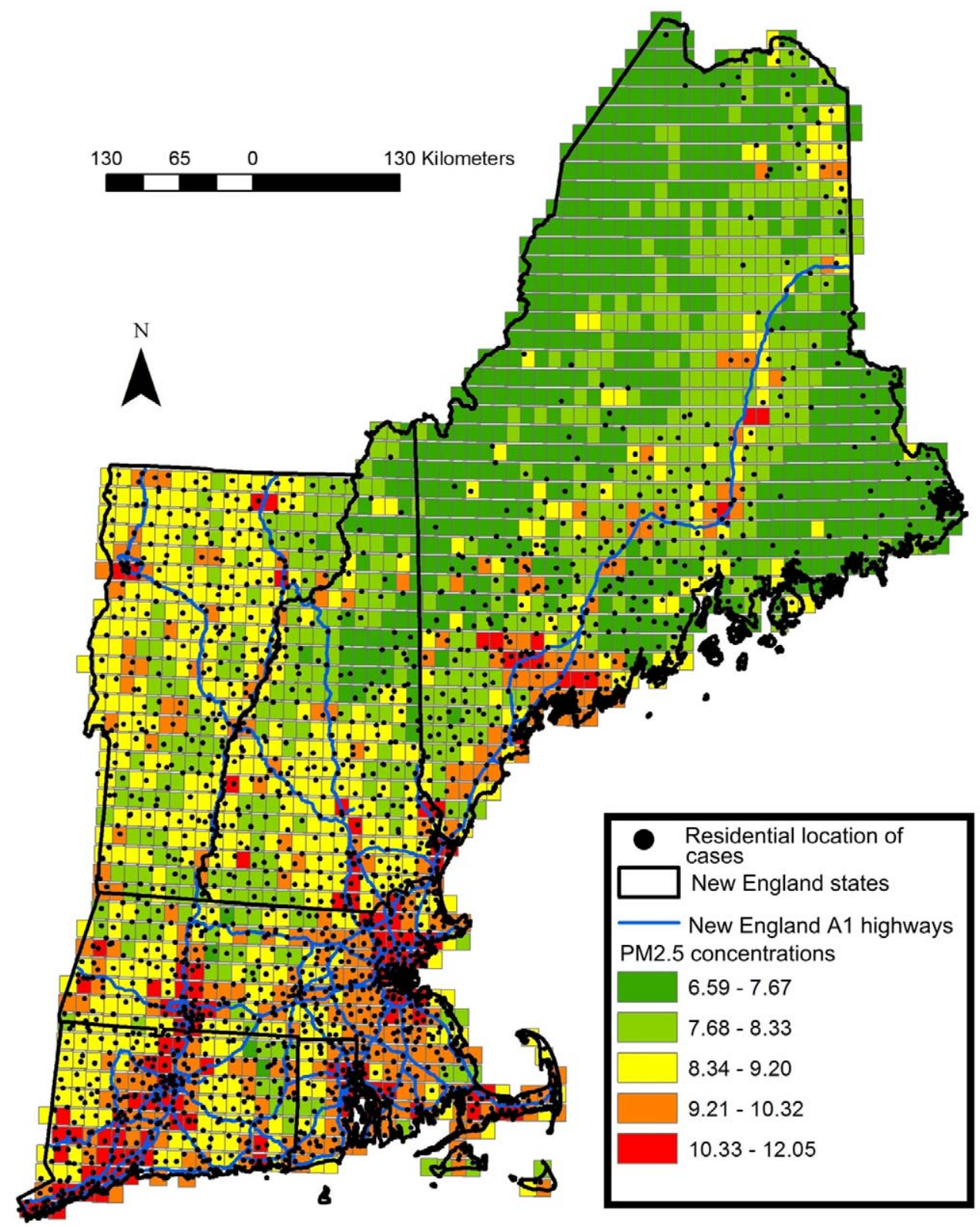

Figure 1: Map of the study area showing the residential location of admission cases juxtaposed over a sample PM2.5 $10 \times 10 \mathrm{~km}$ pollution grid for 01/07/2001.

doi:10.1371/journal.pone.0034664.g001

proportional hazard model noted by Laird and Oliver [37]. This approach allows us to model the time to a hospital admission as a function of both long term and short term exposure simultaneously. Most time series studies have reported stronger associations with mean $\mathrm{PM}_{2.5}$ taken over the current and previous day as compared to same day exposure [38]; therefore for the short-term exposure we used the mean of $\mathrm{PM}_{2.5}$ on the day of admission and day before admission in all models. Long-term exposure was calculated as the mean exposure in each zip-code across the whole study period ( 7 years). Short term exposure was defined as the difference between the two day average and the long-term average. To check the linearity of main effects investigated we fit a piecewise linear model estimating the effect of PM for levels below and above the median of short and long term $\mathrm{PM}_{2.5}$. We did not find a significantly different effect between the two slopes above and below the median which suggests a linear relationship of these variables.

The basic model takes advantage of the fact that a hierarchical mixed Poisson regression can capture both acute and chronic effects. Specifically, we assume that the admission rate $\lambda_{\text {it }}$ in the $i^{\text {th }}$ cell on the $t^{\text {th }}$ day can be modeled as follows:

$$
\begin{aligned}
& \log \left(\lambda_{i t}\right)=\lambda_{i}+\beta_{1} \Delta P M_{i t}+\lambda(t)+\text { temporal covariates } \\
& \text { where } \\
& \lambda_{i}=\delta+\gamma P M_{i .}+\text { spatial covariates }+e_{i}
\end{aligned}
$$

where $\lambda_{\mathrm{i}}$ is the long term admission rate in grid cell $\mathrm{i}, \Delta \mathrm{PM}_{\mathrm{it}}$ is the deviation of the $\mathrm{PM}_{2.5}$ concentration in cell $\mathrm{i}$ from its long term average on day $t, \lambda(t)$ is a smooth function of time, temporal 
Table 1. Descriptive statistics stratified by long term exposure: Hospital admissions by type of admission across New-England for the years 2000-2006.

\begin{tabular}{|c|c|c|c|c|}
\hline \multirow{2}{*}{ Characteristic } & \multirow{2}{*}{$\begin{array}{l}\text { All Respiratory } \\
\text { No. (\%) }\end{array}$} & \multirow{2}{*}{$\frac{\text { CVD }}{\text { No. (\%) }}$} & \multirow{2}{*}{$\begin{array}{l}\text { Stroke } \\
\text { No. (\%) }\end{array}$} & \multirow{2}{*}{$\begin{array}{l}\text { Diabetes } \\
\text { No. (\%) }\end{array}$} \\
\hline & & & & \\
\hline \multicolumn{5}{|l|}{ Low pollution } \\
\hline \multicolumn{5}{|l|}{ Sex } \\
\hline Male & $89241(44.63)$ & $131234(45.52)$ & 24066(41.71) & 77553(43.59) \\
\hline Female & $11073(55.37)$ & 157039(54.48) & $33638(58.29)$ & $100382(56.41)$ \\
\hline \multicolumn{5}{|l|}{ Race } \\
\hline White & $192257(94.41)$ & 277404(96.23) & $55112(95.51)$ & 165174(92.83) \\
\hline Black & $3321(1.66)$ & $4885(1.69)$ & $1186(2.06)$ & 6339(3.56) \\
\hline other & $4395(2.20)$ & $5984(2.08)$ & $1406(2.44)$ & $6422(3.61)$ \\
\hline Age & 79.55 & 79.24 & 80.30 & 77.24 \\
\hline \multicolumn{5}{|l|}{ High pollution } \\
\hline \multicolumn{5}{|l|}{ Sex } \\
\hline Male & $101629(44.52)$ & $148566(44.55)$ & $27516(40.66)$ & $93918(42.56)$ \\
\hline Female & $126658(55.48)$ & $184948(55.45)$ & 40162(59.34) & $126743(57.44)$ \\
\hline \multicolumn{5}{|l|}{ Race } \\
\hline White & 213519 (93.53) & $312202(93.61)$ & 62741(92.71) & 194360(88.08) \\
\hline Black & 7672 (3.36) & $11920(3.57)$ & $2920(4.31)$ & $15682(7.11)$ \\
\hline other & 7096 (3.11) & 9392( 2.82) & $2017(2.98)$ & 10619(4.81) \\
\hline Age & 79.64 & 79.31 & 80.27 & 77.26 \\
\hline
\end{tabular}

doi:10.1371/journal.pone.0034664.t001

covariates are temperature and day of the week, $\mathrm{PM}_{\mathrm{i}}$ is the long term average PM concentration in cell $i$, spatial covariates are socioeconomic factors defined at the zipcode level, and $e_{i}$ is the remaining unexplained difference in admission rate between cell $\mathrm{i}$ and other cells, which is treated as a mean zero normal random effect with variance estimated from the data. This model combines the usual Poisson time series analysis with a Poisson representation of a piecewise-constant proportional hazards model. The resulting model specifies that each time interval defining the constant hazards has a separate intercept, and an offset representing person-time at risk. Since the entire population is being analyzed, and specific admissions cases by type are rare events, the persontime at risk varies slowly and smoothly across time. In the limit as the time interval gets small, the time-period specific intercept also approaches a smooth function of time, and hence both can be replaced with the smooth function of time, $\lambda(t)$.

The specific covariates we used were temperature with the same moving average as $\mathrm{PM}_{2.5}$, age, percent minorities, median income and percent of people with no high school education. $\lambda(\mathrm{t})$ was estimated with a natural cubic spline with 35 degrees of freedom (5 df per year).

To investigate the robustness of our results various sensitivity analysis were run on the all respiratory admission as a sample group. We analyzed other averaging periods (lag1,lag2 vs lag0) and the addition of the land use and temporal variables (percent of, percent of house owners living in owned house, Percent of occupied housing units with more than one person per room and median home value, absolute humidity).

We also wanted to compare the results from our novel prediction models with an analysis of this data base using a traditional time series approach. We ran the analysis for the Boston area (Suffolk, Norfolk and Middlesex counties) using daily admission counts for all respiratory admissions, $\mathbf{P M}_{2.5}$ from a central PM monitor (Countway monitor at Harvard school of public health) and temperature data from Logan airport as commonly done in time series analysis.

Table 2. Descriptive statistics for short term $\mathrm{PM}_{2.5}$ exposure, long term $\mathrm{PM}_{2.5}$ exposure and temperature in New-England for 20002006.

\begin{tabular}{|c|c|c|c|c|c|c|c|c|c|c|}
\hline Covariate & Mean & Min & Max & Median & SD & Range & IQR & Q1 & Q3 & $\begin{array}{l}\text { Days of data } \\
\text { available }\end{array}$ \\
\hline $\begin{array}{l}\text { Lago } \mathrm{PM}_{2.5} \text { (acute } \\
\text { PM) }\end{array}$ & 9.60 & 0.01 & 72.59 & 8.55 & 4.90 & 72.59 & 5.32 & 6.35 & 11.67 & 2557 \\
\hline $\begin{array}{l}1 \text { year } \mathrm{PM}_{2.5} \\
\text { (Chronic PM) }\end{array}$ & 9.65 & 3.54 & 17.79 & 9.65 & 0.81 & 14.25 & 0.98 & 9.16 & 10.14 & 2557 \\
\hline Temperature & 46.52 & -23.80 & 90.10 & 47.90 & 18.73 & 113.90 & 29.30 & 33.00 & 62.30 & 2557 \\
\hline
\end{tabular}

Note: $\mathrm{Q} 1$ and $\mathrm{Q} 3$ are quartiles.

doi:10.1371/journal.pone.0034664.t002 


\section{Results}

Descriptive statistics stratified by long term pollution (high and low split by the mean) are presented in Table 1 . The majority of people included in our analyses which were admitted to hospital were white $(84.92 \%-96.23 \%$ across all admission causes) while the average age was $76.65-80.30$ years.

Table 2 contains a summary of the predicted exposures for both the acute exposure ( 0 day lag) and the chronic exposure (365 day moving average) across all grid cells in the analysis.

Table 3 presents the estimated percent increase in hospital admissions for a $10 \mu \mathrm{g} / \mathrm{m}^{3}$ increase for both short term and long term $\mathrm{PM}_{2.5}$ by cause of admission and associated $95 \%$ confidence intervals. For all respiratory, for every $10-\mu \mathrm{g} / \mathrm{m}^{3}$ increase in short term $\mathrm{PM}_{2.5}$ exposure there is a 0.70 percent increase in admissions $(95 \% \mathrm{CI}=0.35$ to 0.52$)$ while concurrently for every $10-\mu \mathrm{g} / \mathrm{m}^{3}$ increase in long term $\mathrm{PM}_{2.5}$ exposure there is a 4.22 percent increase in admission (95\% CI $=1.06$ to 4.75$)$. For CVD, for every $10-\mu \mathrm{g} / \mathrm{m}^{3}$ increase in short term $\mathrm{PM}_{2.5}$ exposure there is a 1.03 percent increase in admission rate $(95 \% \mathrm{CI}=0.69$ to 0.45$)$ while concurrently for every $10-\mu \mathrm{g} / \mathrm{m}^{3}$ increase in long term $\mathrm{PM}_{2.5}$ exposure there is a 3.12 percent increase in admission $(95 \%$ $\mathrm{CI}=0.30$ to 4.29$)$. For strokes, for every $10-\mu \mathrm{g} / \mathrm{m}^{3}$ increase in short term $\mathrm{PM}_{2.5}$ exposure there is a 0.24 percent increase in admissions $(95 \% \mathrm{CI}=-0.13$ to 0.56$)$ while concurrently for every $10-\mu \mathrm{g} / \mathrm{m}^{3}$ increase in long term $\mathrm{PM}_{2.5}$ exposure there is a 3.49 percent increase in admissions $(95 \% \mathrm{CI}=0.09$ to 5.18 ). Finally for diabetes, for every $10-\mu \mathrm{g} / \mathrm{m}^{3}$ increase in short term $\mathrm{PM}_{2.5}$ exposure there is a 0.96 percent increase in admissions $(95 \% \mathrm{CI}=0.62$ to $0.5 \mathrm{l})$ while concurrently for every $10-\mu \mathrm{g} / \mathrm{m}^{3}$ increase in long term $\mathrm{PM}_{2.5}$ exposure there is a 6.33 percent increase in admissions (CI $=3.22$ to 4.59$)$.

The results from the sensitivity analysis are presented in table 4 . In general the results of the sensitivity analysis were consistent with the primary analysis for the added spatial variables and added temporal variable as well as for the different lags (excluding the acute $\mathrm{PM}_{2.5}$ exposure in lag02).

The results from the classic times series analysis were similar to the main model (1.51 vs 0.72 percent change) albeit with higher standard error (0.002 vs 0.001) and much larger CI (0.42-1.65 Vs. $0.35-0.52)$.

The crude and final estimates as well as the estimates for the model covariates are presented in appendix S1 and S2.

\section{Discussion}

In this paper we report, for the first time, that long term exposure to $\mathrm{PM}_{2.5}$ is associated with increased hospital admissions of the elderly (aged 65 and older) for all respiratory, CVD, stroke, and diabetes. As with mortality studies, this long term impact is higher than the acute effects. Importantly, we continue to see acute effects independent of the chronic effects. In addition, this analysis covers all zip codes in New England, not just subset zipcodes locations near $\mathrm{PM}_{2.5}$ monitors. This represents an important extension of previous Medicare analyses, since we now have estimates that include suburban, small town, and rural populations. Finally, the use of a spatiotemporal model reduces exposure misclassification that exists in, for example time series studies that use a single exposure metric for daily exposure in an entire metropolitan area. Such error is a mixture of classical exposure error, which likely biases the effect estimates downward, and Berkson error, which increases the confidence interval [39]. The results from our novel method presented much tighter confidence intervals compared to the classic time series analysis, indicating that our method could potentially reduce measurement error. Another advantage our method adds is the ability to include population that lives far from monitor compared to the traditional methods

One of the key components of this study is that we showed that by using our prediction models (which produce daily $\mathrm{PM}_{2.5}$ predictions) we are able to simultaneously examine short term and long term association with hospital admissions and to do it for the entire population of New England, avoiding issues of selection or non-representative samples, and accounting for small area measures of potential confounders.

The putative biological mechanisms linking both short term and long term exposure to air pollution and CVD involve direct effects of pollutants on the cardiovascular system, blood, and lung receptors, and/or indirect effects mediated through pulmonary oxidative stress and inflammatory responses [40]. The biological mechanisms linking both short term and long term exposure to air pollution and respiratory diseases include reduced lung function, pulmonary inflammation and oxidative stress [41]. Further, an intervention trial of air filtration for elderly adults reduced particles levels and reported improved endothelial function [42]. Similarly, a trial comparing blood pressure when subjects were walking in Beijing with our without a particle filter reported blood pressure was lower when wearing the filter208.

These studies are also supported by toxicologic indicators of mechanism. For example, a recent study of mice genetically prone to atherosclerosis and on a high fat western diet exposed to concentrated particles from the outside air showed that the particle exposure lead to more atherosclerotic plaque, and increased macrophages and tissue factor in the plaques, which reduce plaque stability and increase the risk of a heart attack [43]. Another study, using a different mouse model of atherosclerosis, documented that particle exposure increased oxidation of LDL, increased the thickness of the arterial wall, and promoted plaque growth and instability [44]. A number of studies have directly linked particle

Table 3. Estimated percent increase in hospital admissions for a $10 \mu \mathrm{g} / \mathrm{m}^{3}$ increase for both short term and long term $\mathrm{PM} \mathrm{L}_{2.5}$ by cause of admission.

\begin{tabular}{|c|c|c|c|c|}
\hline \multirow{2}{*}{$\mathrm{PM}_{2.5}$ exposure type } & \multirow{2}{*}{$\begin{array}{l}\text { All Respiratory } \\
\text { Percent increase }^{\mathbf{a}}\end{array}$} & \multirow{2}{*}{$\frac{\text { CVD }}{\text { Percent increase }^{a}}$} & \multirow{2}{*}{$\begin{array}{l}\text { Stroke } \\
\text { Percent increase }^{a}\end{array}$} & \multirow{2}{*}{$\frac{\text { Diabetes }}{\text { Percent increase }^{a}}$} \\
\hline & & & & \\
\hline $\begin{array}{l}\text { Short term } \mathrm{PM}_{2.5} \\
\text { exposure }\end{array}$ & $0.70(0.35-0.52)$ & $1.03(0.69-0.45)$ & $0.24(-0.13-0.56)$ & $0.96(0.62-0.51)$ \\
\hline $\begin{array}{l}\text { Long term } \mathrm{PM}_{2.5} \\
\text { exposure }\end{array}$ & $4.22(1.06-4.75)$ & $3.12(0.30-4.29)$ & $3.49(0.09-5.18)$ & $6.33(3.22-4.59)$ \\
\hline
\end{tabular}

Note: ${ }^{a}$ Values are percent.

doi:10.1371/journal.pone.0034664.t003 
Table 4. Sensitivity analysis (estimated percent increase in hospital admissions for a $10 \mu \mathrm{g} / \mathrm{m}^{3}$ increase in chronic $P M_{2.5}$ exposure) for all respiratory admission causes.

\begin{tabular}{|c|c|c|}
\hline \multirow[t]{2}{*}{$\mathrm{PM}_{2.5}$ exposure type } & \multirow{2}{*}{$\begin{array}{l}\text { All Respiratory-acute } \mathbf{P M}_{2.5} \\
\text { Percent increase }\end{array}$} & \multirow{2}{*}{$\begin{array}{l}\text { All Respiratory-chronic } \mathrm{PM}_{2.5} \\
\text { Percent increase }^{\mathrm{a}}\end{array}$} \\
\hline & & \\
\hline Baseline & $0.70(0.35-0.52)$ & $4.22(1.06-4.75)$ \\
\hline Added SES variable & $0.70(0.35-0.52)$ & $3.84(0.67-4.74)$ \\
\hline Added temporal variable lag 0 & $0.58(0.23-0.52)$ & $4.40(1.36-4.56)$ \\
\hline Added temporal variable lag 01 & $0.35(0.01-0.52)$ & $4.65(1.60-4.57)$ \\
\hline Added temporal variables lag 02 & $-0.18(-0.52--0.52)$ & $5.32(2.25-4.57)$ \\
\hline
\end{tabular}

Note: ${ }^{a}$ Values are percent.

doi:10.1371/journal.pone.0034664.t004

exposure with ischemia. Wellenius exposed dogs to either filtered air or concentrated air particles, followed by a temporary occlusion of the coronary artery. The animals exposed to particles experienced greater ischemia than those exposed to filtered air $[45,46]$.

Several studies suggested an enhanced susceptibility of people with diabetes to exposure to air pollution partly due to inflammatory mechanisms $[19,20,47]$. In addition there are reports associating air pollution with incidence of diabetes [48].

Our estimated associations between short term exposure to $\mathrm{PM}_{2.5}$ and hospital admissions revealed results qualitatively similar to those studies previously published analyzing short term $\mathrm{PM}_{2.5}$ and hospital admissions $[10,21,49]$. To the best of our knowledge there are no studies on exposure to long term $\mathrm{PM}_{2.5}$ and hospital admissions. However our long term exposure results for CVD are in agreement with those reported by Miller et al. [50], who studied postmenopausal women without previous GVD in 36 U.S. metropolitan areas from 1994 to 1998. They estimated that each $10 \mu \mathrm{g} / \mathrm{m}^{3}$ increase in $\mathrm{PM}_{2.5}$ was associated with a $24 \%$ increase in the risk of a cardiovascular event (hazard ratio, 1.24; 95\% $\mathrm{CI}=1.09$ to 1.41 ). Those events would almost certainly have resulted in hospitalizations.

These findings also clarify a previous apparent inconsistency. Cohort studies of the association of PM2.5 and deaths from CVD or stroke have reported much larger effect sizes than the time series studies of PM2.5 and admissions from those causes $[51,52,53,54]$. This seems implausible since many of those events result in hospitalizations. However, these chronic mortality estimates are also much larger than the time series estimates of the acute effects of recent PM2.5 exposure on deaths from those causes. The usual explanation is that chronic exposure produces greater effects because it leads to cumulative damage, such as atherosclerosis etc. $[55,56,57,58,59]$. Those arguments would be equally applicable to the effects of long term exposure on chronic rates of admissions for these causes. In this paper we show that such larger effects in fact are seen.

A major limitation of this study is our limited ability to control for individual level potential confounders, such as socio-economic factors, diet, exercise, etc. We have used area-based measures of socio-economic factors. To test the potential for confounding, we

\section{References}

1. Brunekreef B, Holgate ST (2002) Air pollution and health. The lancet 360: 1233-1242.

2. Pope CA, Dockery DW, Schwartz J (1995) Review of epidemiological evidence of health effects of particulate air pollution. Inhalation toxicology 7: 1-18.

3. Schwartz J (1994) Air pollution and hospital admissions for the elderly in Birmingham, Alabama. Am J Epidemiol 139: 589. used data from the Normative Aging Study [60,61], a population based study of an aging cohort, resident in Maine, Massachusetts, New Hampshire and Rhode Island As a general population of subjects eligible for Medicare, we think this is a reasonable test of the potential for confounding. We assigned the same 365 day average exposure to those participants from our model, and examined the association with packyears, with physical activity (METS), and with dietary fish intake. In no case was there a significant association.

Another limitation of the present study is the relatively coarse spatial resolution of $10 \times 10 \mathrm{~km}$. However, as satellite remote sensing evolves and progresses, higher spatial resolution data $(3 \times 3 \mathrm{~km}$ and $1 \times 1 \mathrm{~km})$ should become available which will further reduce exposure error. Such finer resolution should enable us to assess more precise estimated daily individual exposure as they relate to different location such as residence, work place etc.

In conclusion, we have demonstrated how our prediction models perform well in assessing short term and long term human exposures. Our findings indicate that hospital admission were associated with both short term and long term exposure to $\mathrm{PM}_{2.5}$. These findings present new opportunities to study the effects of both the long and short term exposure and human health.

\section{Supporting Information}

Appendix S1 Crude estimates vs. Final model estimates. (DOCX)

Appendix S2 Estimates of model covariates. (DOCX)

\section{Acknowledgments}

The authors want to thank Steven J. Melly, Department of Environmental Health, Harvard School of Public Health, Harvard University.

\section{Author Contributions}

Conceived and designed the experiments: IK JS. Performed the experiments: IK AZ BC. Analyzed the data: IK PK BC AZ JS, Contributed reagents/materials/analysis tools: BC. Wrote the paper: IK JS.

4. Spix C, Anderson HR, Schwartz J, Vigotti MA, Letertre A, et al. (1998) Shortterm effects of air pollution on hospital admissions of respiratory diseases in Europe: a quantitative summary of APHEA study results. Archives of Environmental Health: An International Journal 53: 54-64. 
5. Zanobetti A, Franklin M, Koutrakis P, Schwartz J (2009) Fine particulate air pollution and its components in association with cause-specific emergency admissions. Environmental Health 8: 58.

6. Zanobetti A, Schwartz J, Dockery DW (2000) Airborne particles are a risk factor for hospital admissions for heart and lung disease. Environ Health Perspect 108: 1071.

7. Dominici F, Peng RD, Bell ML, Pham L, McDermott A, et al. (2006) Fine particulate air pollution and hospital admission for cardiovascular and respiratory diseases. Jama 295: 1127.

8. Fusco D, Forastiere F, Michelozzi P, Spadea T, Ostro B, et al. (2001) Air pollution and hospital admissions for respiratory conditions in Rome, Italy. European respiratory journal 17: 1143.

9. Schwartz J (1996) Air pollution and hospital admissions for respiratory disease. Epidemiology 7: 20-28.

10. Mann JK, Tager IB, Lurmann F, Segal M, Quesenberry CP Jr., et al. (2002) Air pollution and hospital admissions for ischemic heart disease in persons with congestive heart failure or arrhythmia. Environ Health Perspect 110: 1247.

11. Schwartz J, Morris R (1995) Air pollution and hospital admissions for cardiovascular disease in Detroit, Michigan. Am J Epidemiol 142: 23-35.

12. Schwartz J (1997) Air pollution and hospital admissions for cardiovascular disease in Tucson. Epidemiology 8: 371-377.

13. D'Ippoliti D, Forastiere F, Ancona C, Agabiti N, Fusco D, et al. (2003) Air pollution and myocardial infarction in Rome: a case-crossover analysis. Epidemiology 14: 528.

14. Zanobetti A, Schwartz J (2005) The effect of particulate air pollution on emergency admissions for myocardial infarction: a multicity case-crossover analysis. Environ Health Perspect 113: 978-982.

15. Symons J, Wang L, Guallar E, Howell E, Dominici F, et al. (2006) A casecrossover study of fine particulate matter air pollution and onset of congestive heart failure symptom exacerbation leading to hospitalization. Am J Epidemiol 164: 421.

16. Wellenius GA, Bateson TF, Mittleman MA, Schwartz J (2005) Particulate air pollution and the rate of hospitalization for congestive heart failure among Medicare beneficiaries in Pittsburgh, Pennsylvania. Am J Epidemiol 161: 1030.

17. Ilabaca M, Olaeta I, Campos E, Villaire J, Tellez-Rojo MM, et al. (1999) Association between levels of fine particulate and emergency visits for pneumonia and other respiratory illnesses among children in Santiago, Chile. JOURNAL-AIR AND WASTE MANAGEMENT ASSOCIATION 49: $154-163$.

18. Medina-Ramon M, Zanobetti A, Schwartz J (2006) The effect of ozone and PM10 on hospital admissions for pneumonia and chronic obstructive pulmonary disease: a national multicity study. Am J Epidemiol 163: 579.

19. O'Neill MS, Veves A, Zanobetti A, Sarnat JA, Gold DR, et al. (2005) Diabetes enhances vulnerability to particulate air pollution-associated impairment in vascular reactivity and endothelial function. Circulation 111: 2913.

20. Zanobetti A, Schwartz J (2001) Are diabetics more susceptible to the health effects of airborne particles? Am J Respir Crit Care Med 164: 831

21. Dominici F, Peng RD, Bell ML, Pham L, McDermott A, et al. (2006) Fine particulate air pollution and hospital admission for cardiovascular and respiratory diseases. Jama 295: 1127-1134.

22. Zanobetti A, Franklin M, Koutrakis P, Schwartz J (2009) Fine particulate air pollution and its components in association with cause-specific emergency admissions. Environ Health 8: 58-70.

23. Andersen ZJ, Bønnelykke K, Hvidberg M, Jensen SS, Ketzel M, et al. (2011) Long-term exposure to air pollution and asthma hospitalisations in older adults: a cohort study. Thorax.

24. Hruba F, Fabianova E, Koppova K, Vandenberg JJ (2001) Childhood respiratory symptoms, hospital admissions, and long-term exposure to airborne particulate matter. Journal of Exposure Analysis and Environmental Epidemiology 11: 33.

25. Oudin A, Strömberg U, Jakobsson K, Stroh E, Lindgren AG, et al. (2010) Hospital Admissions for Ischemic Stroke: Does Long-Term Exposure to Air Pollution Interact with Major Risk Factors. Cerebrovascular Diseases 31: $284-293$.

26. Andersen ZJ, Raaschou-Nielsen O, Ketzel M, Jensen SS, Hvidberg M, et al. (2012) Diabetes Incidence and Long-Term Exposure to Air Pollution. Diabetes Care 35: 92-98.

27. Gryparis A, Paciorek CJ, Zeka A, Schwartz J, Coull BA (2009) Measurement error caused by spatial misalignment in environmental epidemiology. Biostatistics 10: 258-274.

28. Paciorek CJ, Yanosky JD, Puett RC, Laden F, Suh HH (2009) Practical largescale spatio-temporal modeling of particulate matter concentrations. The Annals of Applied Statistics 3: 370-397.

29. USCB (2000) United States Census Bureau of 2000. US Census Bureau.

30. Engel-Cox J, Holloman C, Coutant B, Hoff R (2004) Qualitative and quantitative evaluation of MODIS satellite sensor data for regional and urban scale air quality. Atmospheric Environment 38: 2495-2509.

31. Gupta P, Christopher S, Wang J, Gehrig R, Lee Y, et al. (2006) Satellite remote sensing of particulate matter and air quality assessment over global cities. Atmospheric Environment 40: 5880-5892.

32. Koelemeijer R, Homan C, Matthijsen J (2006) Comparison of spatial and temporal variations of aerosol optical thickness and particulate matter over Europe. Atmospheric Environment 40: 5304-5315.
33. Liu Y, Park R, Jacob D, Li Q, Kilaru V, et al. (2004) Mapping annual mean ground-level PM2. 5 concentrations using Multiangle Imaging Spectroradiometer aerosol optical thickness over the contiguous United States. J Geophys Res 109: 3269-3278.

34. Kloog I, Koutrakis P, Coull BA, Lee HJ, Schwartz J (2011) Assessing Temporally and Spatially Resolved PM2. 5 Exposures for Epidemiological Studies Using Satellite Aerosol Optical Depth Measurements. Atmospheric Environment.

35. NCDC (2010) The national climatic data center data inventories.

36. Census US (2000) U.S. Census of Population and Housing. Government Printing Office.

37. Laird N, Olivier D (1981) Covariance analysis of censored survival data using $\log$-linear analysis techniques. Journal of the American Statistical Association. pp 231-240.

38. Schwartz J, Dockery DW, Neas LM (1996) Is daily mortality associated specifically with fine particles? Journal of the Air \& Waste Management Association (1995) 46: 927.

39. Zeger SL, Thomas D, Dominici F, Samet JM, Schwartz J, et al. (2000) Exposure measurement error in time-series studies of air pollution: concepts and consequences. Environ Health Perspect 108: 419-426.

40. Brook RD, Franklin B, Cascio W, Hong Y, Howard G, et al. (2004) Air pollution and cardiovascular disease. Circulation 109: 2655-2671.

41. Pope CA, Young B, Dockery D (2006) Health effects of fine particulate air pollution: lines that connect. Journal of the Air \& Waste Management Association 56: 709-742.

42. Brauner EV, Forchhammer L, Moller P, Barregard L, Gunnarsen L, et al. (2008) Indoor particles affect vascular function in the aged: an air filtrationbased intervention study. Am J Respir Crit Care Med 177: 419-425.

43. Sun Q, Yue P, Kirk RI, Wang A, Moatti D, et al. (2008) Ambient air particulate matter exposure and tissue factor expression in atherosclerosis. Inhal Toxicol 20: 127-137.

44. Soares SR, Carvalho-Oliveira R, Ramos-Sanchez E, Catanozi S, da Silva LF, et al. (2009) Air pollution and antibodies against modified lipoproteins are associated with atherosclerosis and vascular remodeling in hyperlipemic mice. Atherosclerosis 207: 368-373.

45. Bartoli GR, Wellenius GA, Coull BA, Akiyama I, Diaz EA, et al. (2009) Concentrated ambient particles alter myocardial blood flow during acute ischemia in conscious canines. Environ Health Perspect 117: 333-337.

46. Wellenius GA, Coull BA, Godleski JJ, Koutrakis P, Okabe K, et al. (2003) Inhalation of concentrated ambient air particles exacerbates myocardial ischemia in conscious dogs. Environ Health Perspect 111: 402-408.

47. Baja ES, Schwartz JD, Wellenius GA, Coull BA, Zanobetti A, et al. (2010) Traffic-related air pollution and QT interval: modification by diabetes, obesity, and oxidative stress gene polymorphisms in the normative aging study. Environ Health Perspect 118: 840-846.

48. Kramer U, Herder C, Sugiri D, Strassburger K, Schikowski T, et al. (2010) Traffic-related air pollution and incident type 2 diabetes: results from the SALIA cohort study. Environ Health Perspect 118: 1273-1279.

49. Wellenius GA, Schwartz J, Mittleman MA (2005) Air pollution and hospital admissions for ischemic and hemorrhagic stroke among Medicare beneficiaries. Stroke 36: 2549.

50. Miller KA, Siscovick DS, Sheppard L, Shepherd K, Sullivan JH, et al. (2007) Long-term exposure to air pollution and incidence of cardiovascular events in women. New England Journal of Medicine 356: 447-458.

51. Krewski D, Jerrett M, Burnett RT, Ma R, Hughes E, et al. (2009) Extended follow-up and spatial analysis of the American Cancer Society study linking particulate air pollution and mortality. Res Rep Health Eff Inst: 5-114; discussion 115-136.

52. Laden F, Neas LM, Dockery DW, Schwartz J (2000) Association of fine particulate matter from different sources with daily mortality in six US cities. Environ Health Perspect 108: 941.

53. Ostro B, Lipsett M, Reynolds P, Goldberg D, Hertz A, et al. (2010) Long-term exposure to constituents of fine particulate air pollution and mortality: results from the California Teachers Study. Environ Health Perspect 118: 363.

54. Puett R, Hart J, Yanosky J, Paciorek C, Schwartz J, et al. (2009) Chronic fine and coarse particulate exposure, mortality, and coronary heart disease in the Nurses' Health Study. Environ Health Perspect 117: 1702.

55. Adar SD, Klein R, Klein BEK, Szpiro AA, Cotch MF, et al. (2010) Air pollution and the microvasculature: a cross-sectional assessment of in vivo retinal images in the population-based Multi-Ethnic Study of Atherosclerosis (MESA). PLoS Medicine 7: e1000372

56. Bauer M, Moebus S, Mohlenkamp S, Dragano N, Nonnemacher M, et al. (2010) Urban Particulate Matter Air Pollution Is Associated With Subclinical Atherosclerosis:: Results From the HNR (Heinz Nixdorf Recall) Study. Journal of the American College of Cardiology 56: 1803-1808.

57. Hansen CS, Sheykhzade M, Moller P, Folkmann JK, Amtorp O, et al. (2007) Diesel exhaust particles induce endothelial dysfunction in apoE-/-mice. Toxicology and applied pharmacology 219: 24-32.

58. Künzli N, Jerrett M, Garcia-Esteban R, Basagaña X, Beckermann B, et al. (2010) Ambient air pollution and the progression of atherosclerosis in adults. PLoS One 5: e9096.

59. Sun O, Wang A, Jin X, Natanzon A, Duquaine D, et al. (2005) Long-term air pollution exposure and acceleration of atherosclerosis and vascular inflammation 
in an animal model. JAMA: the journal of the American Medical Association 294: 3003 .

60. Halonen JI, Zanobetti A, Sparrow D, Vokonas PS, Schwartz J (2010) Associations between outdoor temperature and markers of inflammation: a cohort study. Environmental Health 9: 42.
61. Madrigano J, Baccarelli A, Wright RO, Suh H, Sparrow D, et al. (2010) Air pollution, obesity, genes and cellular adhesion molecules. Occup Environ Med 67: 312-317. 